\title{
Comparison between Flexor Carpi Radialis and Flexor Carpi Ulnaris Tendon Transfer for Fingers' Extension in High Radial Nerve Palsy
}

\author{
Sen $\mathrm{SK}^{1}$, Datta $\mathrm{NK}^{2}$, Missra $\mathrm{D}^{3}$, Khan $\mathrm{MZH}^{4}$, Islam J ${ }^{5}$, Sen $\mathrm{S}^{6}$, Chowdhury $\mathrm{RM}^{7}$, ${ }^{*}$ Das $\mathrm{KP}^{8}$
}

\begin{abstract}
The hand grip is severely impaired following high radial nerve palsy due to loss of extension of the wrist, metacarpophalangeal joint of fingers and thumb. If radial nerve does not show neural recovery following conservative or surgical repair during the optimum time, tendon transfer is considered the standard treatment. To evaluate and compare the clinical outcome between flexor carpi radialis and flexor carpiulnaris tendon transfer for fingers' extension in high radial nerve palsy. This randomized controlled trial study was carried out in the Department of Orthopedic Surgery, Bangabandhu Sheikh Mujib Medical University, Dhaka over a period of two years from January 2013 to December 2014. A total of 30 patients with high radial nerve palsy were recruited, 15 patients were gone through Flexor Carpi Radialis tendon transfer procedure (FCR group) and the rest 15 patients were gone through Flexor Carpi Ulnaris tendon transfer procedure(FCU group). The patients were followed up for 12 weeks after surgical intervention. Out of all patients, $86.7 \%$ male were encountered in each group. The mean age was found $31.07 \pm 9.14$ years in FCR group and $33.60 \pm 10.79$ years in FCU group. Humerus fracture was remained a major cause of radial nerve palsy in both FCR and FCU groups (26.7\% vs. $33.3 \%)$. In final follow-up at $12^{\text {th }}$ week, no extension deficit
\end{abstract}

1. Dr. Sumon Kumar Sen, Lieutent Colonel, Dhaka $\mathrm{CMH}$.

2. Professor Dr. Nakul Kumar Datta, Department of Orthopaedics, BSMMU, Dhaka.

3. Dr. Dipendra Misra, Resident, Department of Orthopaedics, BSMMU, Dhaka.

4. Dr. Zahidul Hak Khan, Resident, Department of Orthopaedics, BSMMU, Dhaka.

5. Dr. Jahidul Islam, Resident, Department of Orthopaedics, BSMMU, Dhaka.

6. Dr. Susmita Sen, Assistant Professor, Neonatology Department, BSMMU, Dhaka.

7. Dr. Rumpa Mani Chowdhury, Assistant Professor, Neonatology Department, BSMMU, Dhaka.

8. *Krishna Priya Das, Professor, Hand and Reconstructive surgery, Department of Orthopaedics, BSMMU, Dhaka.

*For correspondence was observed at MCP joint (93.3\% vs. $80.0 \%, p>0.05)$. The end result of surgical intervention was found satisfactory equally in both the groups (86.7\%). In case of high radial nerve palsy, both FCR and FCU tendon transfer procedures are effective forfingers' extension at MCP joint.

Keywords: Flexor carpi radialis, flexor carpi ulnaris, fingers' extension and radial nerve palsy.

\section{INTRODUCTION}

Hand is a highly specialized organ as it has grasping, pinching and hooking function carried out by musculotendinous units. It can give information about the position, size and shape of an object by its highly developed sensory mechanism and described as third eye. ${ }^{1}$

Injury to radial nerve may occur at different level. A very high level radial nerve injury occurs at the level of axilla. Loss of extension at the elbow, wrist, fingers and thumb occur in very high level lesions. A high level radial nerve palsy happens due to injury above elbow to below axilla where elbow function is intact but wrist drop is obvious and associated with loss of fingers and thumb extension. A low level lesion occurs due to injury just below the elbow where elbow and wrist spared but fingers and thumb extension are lost. ${ }^{2}$

Most surgeons have used the pronator teres (PT) to extensor carpi radialis brevis (ECRB) transfer to restore wrist extension. ${ }^{3}$ Restoration of finger extension may be done using the flexor carpi radialis (FCR), flexor carpi ulnaris (FCU) or flexor digitorum superficialis (FDS). ${ }^{4-6}$ Currently many surgeons prefer to use FCR because it is simpler than using the FDS and it spares the strong wrist stabilizer. $^{7}$

The best technique of thumb extensor/radial abduction remains controversial. The most commonly used technique is the transfer of Palmaris longus $(\mathrm{PL})$ to the rerouted extensor pollicis longus (EPL). The EPL must be transposed from the third compartment toward the PL. This transposition eliminates the thumb adduction vector of the EPL and the new 'EPL' then acts as both an extensor and radial abductor of the thumb. ${ }^{3,8}$ Surgeons who do not 
re-route the EPL have addressed radial abduction of the thumb by transferring the PL or FCR to the abductor policis longus (APL). ${ }^{4,5,7}$ Radial abduction of the thumb may also be restored by a tenodesis of the APL to the brachioradialis(BR). ${ }^{7}$

The rationale for choosing the FCR is preservation of the FCU as a strong wrist stabilizer; preservation of wrist flexion with ulnar deviation (hammering activity for manual workers). ${ }^{9}$ Clinical findings may have the significant implication on the choice of the tendon transfer. In general tendon transfer is indicated when there is little or no likelihood that a damage radial nerve will regenerate sufficiently to innervate lost motor function. If the nerve, the extensor muscles supplied by the nerve or both has been damaged beyond repair, tendon transfer should be considered as soon as sufficient wound healing and maturation have occurred to produce tissue equilibrium. ${ }^{10}$

Previous studies recommended for further studies to be carried out to makea comparison between FCR versus FCU tendon transfer for EDC function (fingers' extension) in the cases of high radial nerve palsy. Limited data are available regarding this topic in our country. Available information from above studies had provided a rationale to conduct the current study.

\section{MATERIAL AND METHOD}

This randomized controlled trial was carried out at the Department of Orthopedic Surgery, Bangabandhu Sheikh Mujib Medical University, Dhaka over a period of two years from January 2013 to December 2014. A total of 30 patients with high radial nerve palsy were recruited, 15 patients were gone through Flexor Carpi Radialis tendon transfer procedure (FCR group) and the rest 15 patients were gone through Flexor Carpi Ulnaris tendon transfer procedure (FCU group). Patients had duration of radial nerve injury less than 6 months, stiff joints, epilepsy or paralyzed hand and patients with absence of palmaris longus muscle were excluded from this study. They were diagnosed on the basis of presenting complaints, clinical examinations \& investigations. The patients were followed up for 12 weeks after surgical intervention. In this study, baseline data and four follows up were recorded from each patient and measured the clinical response, complications and Bincaz scalewas used for the overall assessment of tendon transfers for high radial nerve palsy.

\section{RESULTS}

Tabble I shows the range (min-max) (18-46) (11-53). In both groups $13.3 \%$ were female and $86.7 \%$ were male. The mean age was found $31.07 \pm 9.14$ years with the range of 18 to 46 years in FCR group and mean age was $33.60 \pm 10.79$ years with the range of 11 to 53 years in FCU group.

Table I: Demographic profile of the study population $(\mathbf{n}=30)$

\begin{tabular}{|l|c|c|c|}
\hline \multirow{2}{*}{} & \multicolumn{2}{|c|}{ Group } & \multirow{2}{*}{$\begin{array}{c}\text { p } \\
\text { value }\end{array}$} \\
\cline { 2 - 3 } & FCR n (\%) & FCU n (\%) & \multirow{2}{*}{1.000} \\
\hline Gender & $2(13.3)$ & $2(13.3)$ & \\
\hline Female & $13(86.7)$ & $13(86.7)$ & \\
\hline Male & Age (years) & \multicolumn{3}{|l}{} \\
\hline Mean \pm SD) & $31.07 \pm 9.14)$ & $33.60 \pm 10.79)$ & 0.493 \\
\hline
\end{tabular}

Table II shows the soaked dressing in first POD (26.7\% vs. $20.0 \%$ ), second POD (20.0\% vs. $14.3 \%)$ in FCR and FCU group respectively. Hand swelling in first POD was $64.3 \%$ and $53.3 \%$ in second POD; $26.7 \%$ and $20 \%$ in FCR and FCU groups respectively.

Table II: Distribution of the patients according to Post-operative follow-up (n=30)

\begin{tabular}{|l|c|c|c|c|}
\hline \multirow{2}{*}{} & \multicolumn{2}{|c|}{$1^{\text {st }}$ POD } & \multicolumn{2}{c|}{$2^{\text {nd }}$ POD } \\
\cline { 2 - 5 } & $\begin{array}{c}\text { FCR } \\
\mathrm{n}(\%)\end{array}$ & $\begin{array}{c}\text { FCU } \\
\mathrm{n}(\%)\end{array}$ & $\begin{array}{c}\text { FCR } \\
\mathrm{n}(\%)\end{array}$ & $\begin{array}{c}\text { FCU } \\
\mathrm{n}(\%)\end{array}$ \\
\hline Dressing (Soaked) & $4(26.7)$ & $3(20.0)$ & $3(20.0)$ & $2(14.3)$ \\
\hline Hand Swelling & $9(64.3)$ & $8(53.3)$ & $4(26.7)$ & $3(20.0)$ \\
\hline
\end{tabular}

Table III shows the wound condition in both FCR and FCU group (100.0\% vs. $100.0 \%)$. Table III: Distribution of the patients according to
wound condition $(n=30)$

\begin{tabular}{|l|c|c|c|}
\hline \multirow{2}{*}{$\begin{array}{l}\text { Wound condition- } \\
\text { (Healthy) }\end{array}$} & \multicolumn{2}{|c|}{ Group } & \multirow{2}{*}{$\begin{array}{c}\mathrm{P} \\
\mathrm{n}(\%)\end{array}$} \\
\cline { 2 - 3 } & $\begin{array}{c}\text { FCU } \\
\mathrm{n}(\%)\end{array}$ & \\
\hline At 12th week & $15(100)$ & $15(100)$ & \\
\hline
\end{tabular}


Table IV shows the extension deficit $>10^{\circ}$ was found nil in both groups at $12^{\text {th }}$ week after surgical intervention. Extension deficit $<10^{\circ}$ was found $20.0 \%$ in FCR group and $26.7 \%$ in FCU group at $12^{\text {th }}$ week after surgical intervention. No extension deficit was accounted $80.0 \%$ in FCR group and $73.3 \%$ in FCU group at $12^{\text {th }}$ week after surgical intervention.

\section{Table IV: Distribution of the patients according to Finger's active extension $(n=30)$}

\begin{tabular}{|l|c|c|c|}
\hline \multirow{2}{*}{$\begin{array}{l}\text { Finger's active extension } \\
\text { (at } 12^{\text {th }} \text { weeks) }\end{array}$} & \multicolumn{2}{|c|}{ Groups } & \multirow{2}{*}{$\begin{array}{c}\text { P } \\
\text { value }\end{array}$} \\
\cline { 2 - 3 } & FCR n (\%) & FCU n (\%) & \\
\hline Extension deficit $>10^{\circ}$ & - & - & \\
\hline Extension deficit $<10^{\circ}$ & $3(20.0)$ & $4(26.7)$ & $0.666^{\text {ns }}$ \\
\hline No extension deficit & $12(80.0)$ & $11(73.3)$ & \\
\hline
\end{tabular}

Table V shows the fairly satisfaction was found $6.7 \%$ cases in FCR group and $26.7 \%$ cases in FCU group at $12^{\text {th }}$ week after surgical intervention. Satisfied was found $66.7 \%$ in FCR group and $60.0 \%$ in FCU group at $12^{\text {th }}$ week after surgical intervention. Patients with very satisfied were accounted in FCR group was 26.7\% and in FCU groups $13.3 \%$ at $12^{\text {th }}$ week after surgical intervention. No statistically significant difference was found in two groups in cosmetically satisfaction of patients.

Table V: Distribution of the patients according to cosmetically satisfaction of patients $(n=30$.)

\begin{tabular}{|c|c|c|c|}
\hline \multirow{2}{*}{$\begin{array}{l}\text { Cosmetically satisfaction } \\
\text { of patients (at 12th weeks) }\end{array}$} & \multicolumn{2}{|c|}{ Groups } & \multirow{2}{*}{$\begin{array}{c}\mathrm{P} \\
\text { value }\end{array}$} \\
\hline & FCR n (\%) & FCU n (\%) & \\
\hline Fairly satisfied & $1(6.7)$ & $4(26.7)$ & \\
\hline Satisfied & $10(66.7)$ & $9(60.0)$ & 0.657 \\
\hline Very satisfied & $4(26.7)$ & $2(13.3)$ & \\
\hline
\end{tabular}

Table VI shows the follows up at $12^{\text {th }}$ week, $6.7 \%$ patients had extension deficit $<10^{0}$ of metacarpo-phalangeal joint in FCR group but in FCU group, was $20 \%$. No-significant difference in level of metacarpo-phalangeal joint extension was observed.

\section{Table VI: Distribution of the patients according to Metacarpo-phalangeal joint extension at final follow-up at $12^{\text {th }}$ week $(n=30)$.}

\begin{tabular}{|l|c|c|c|}
\hline \multirow{2}{*}{$\begin{array}{l}\text { Metacarpophalangeal } \\
\text { joint extension } \\
\text { (at 12th weeks) }\end{array}$} & $\begin{array}{c}|c| \\
\text { FCR } \\
\text { n }(\%)\end{array}$ & $\begin{array}{c}\text { FCU } \\
\text { value }\end{array}$ & \\
\hline Extension deficit $>100$ & - & - & \multirow{2}{*}{$0.591 \mathrm{~ns}$} \\
\hline Extension deficit $<100$ & $1(6.7)$ & $3(20.0)$ & \\
\hline No extension deficit & $14(93.3)$ & $12(80.0)$ & \\
\hline
\end{tabular}

Table VII shows that no significant difference was found regarding overall satisfaction between both groups $(93.3 \%$ vs. $80.0 \%$ ). In FCR group $93.3 \%$ of the patientsand in FCU group, $86.7 \%$ of the patients able to return their previous job.

Table VII: Distribution of the patients according to overall satisfaction of patients with the operation $(n=30)$.

\begin{tabular}{|l|c|c|c|}
\hline & \multicolumn{2}{|c|}{ Groups } & \multirow{2}{*}{ P value } \\
\cline { 2 - 3 } & FCR n (\%) & FCU n (\%) & \\
\hline Overall Satisfaction & $14(93.3)$ & $12(80.0)$ & $0.591 \mathrm{~ns}$ \\
\hline Able to return previous job & $14(93.3)$ & $13(86.7)$ & $0.543 \mathrm{~ns}$ \\
\hline
\end{tabular}

Table VIII shows the end result of surgical intervention excellent in FCR group and FCU group $26.7 \%$ vs. 6.7\%, (p>0.5). 60.0\% and $80.0 \%$ patients declared as good surgical intervention in FCR and FCU group respectively. Fair surgical intervention was found same in both groups which was $13.3 \%$. There was no significant differencein surgical intervention between two groups.

Table VIII: Distribution of the patients according to end result of surgical intervention $(n=30)$

\begin{tabular}{|l|c|c|l|}
\hline \multirow{2}{*}{ Result } & \multicolumn{2}{|c|}{ Groups } & \multirow{2}{*}{ P value } \\
\cline { 2 - 3 } & FCR n (\%) & FCU n (\%) & \\
\hline Excellent & $4(26.7)$ & $1(6.7)$ & \\
\hline Good & $9(60.0)$ & $12(80.0)$ & $0.308 \mathrm{~ns}$ \\
\hline Fair & $2(13.3)$ & $2(13.3)$ & \\
\hline
\end{tabular}

Table IX shows the among the 30 case, complications developed in $8(26.66 \%)$ of cases, but $3(20 \%)$ of case in FCR group and 5(33.33\%) of cases in FCU group. Those patient developed infection subsequently developed adhesion formation and extension or flexion lag. There was no statistical difference between two groups.

Table IX: Distribution of the study population by complications $(\mathbf{n}=30)$

\begin{tabular}{|l|c|c|c|}
\hline \multirow{2}{*}{ Complication } & \multicolumn{2}{|c|}{ Groups } & \multirow{2}{*}{ p value } \\
\cline { 2 - 3 } & FCR n (\%) & FCU n (\%) & \\
\hline Infection & $2(13.3)$ & $2(13.3)$ & $0.881 \mathrm{~ns}$ \\
\hline Adhesion formation & $2(13.3)$ & $3(20.0)$ & \\
\hline Ugly scar & $2(13.3)$ & $2(13.3)$ & \\
\hline Muscle bulging & $1(6.7)$ & $3(20.0)$ & \\
\hline Extension lag & $1(6.7)$ & $1(6.7)$ & \\
\hline Flexion lag & $1(6.7)$ & $1(6.7)$ & \\
\hline
\end{tabular}

Complications were almost same in both groups. 


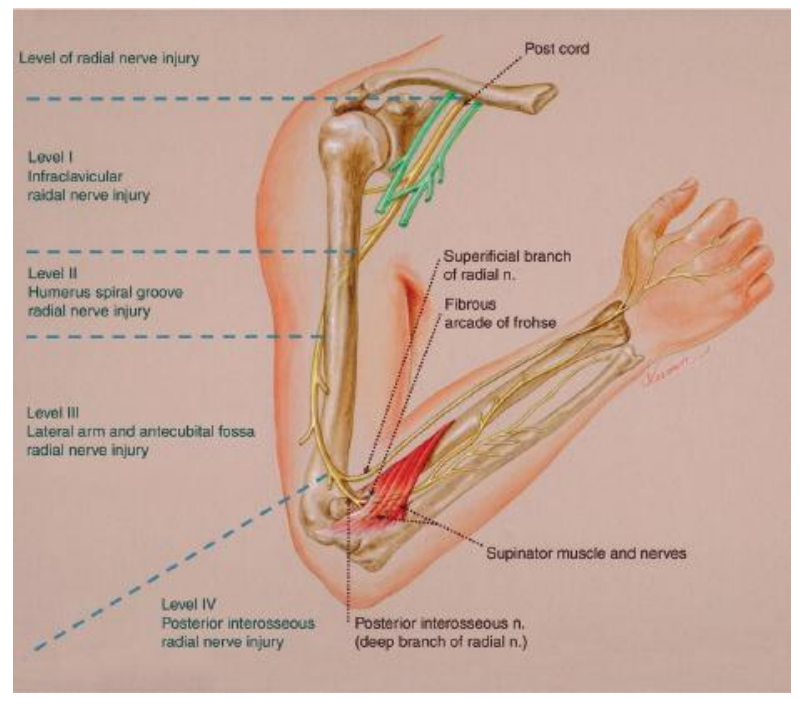

FCU set of Tendon Transfer for High Radial Nerve Palsy
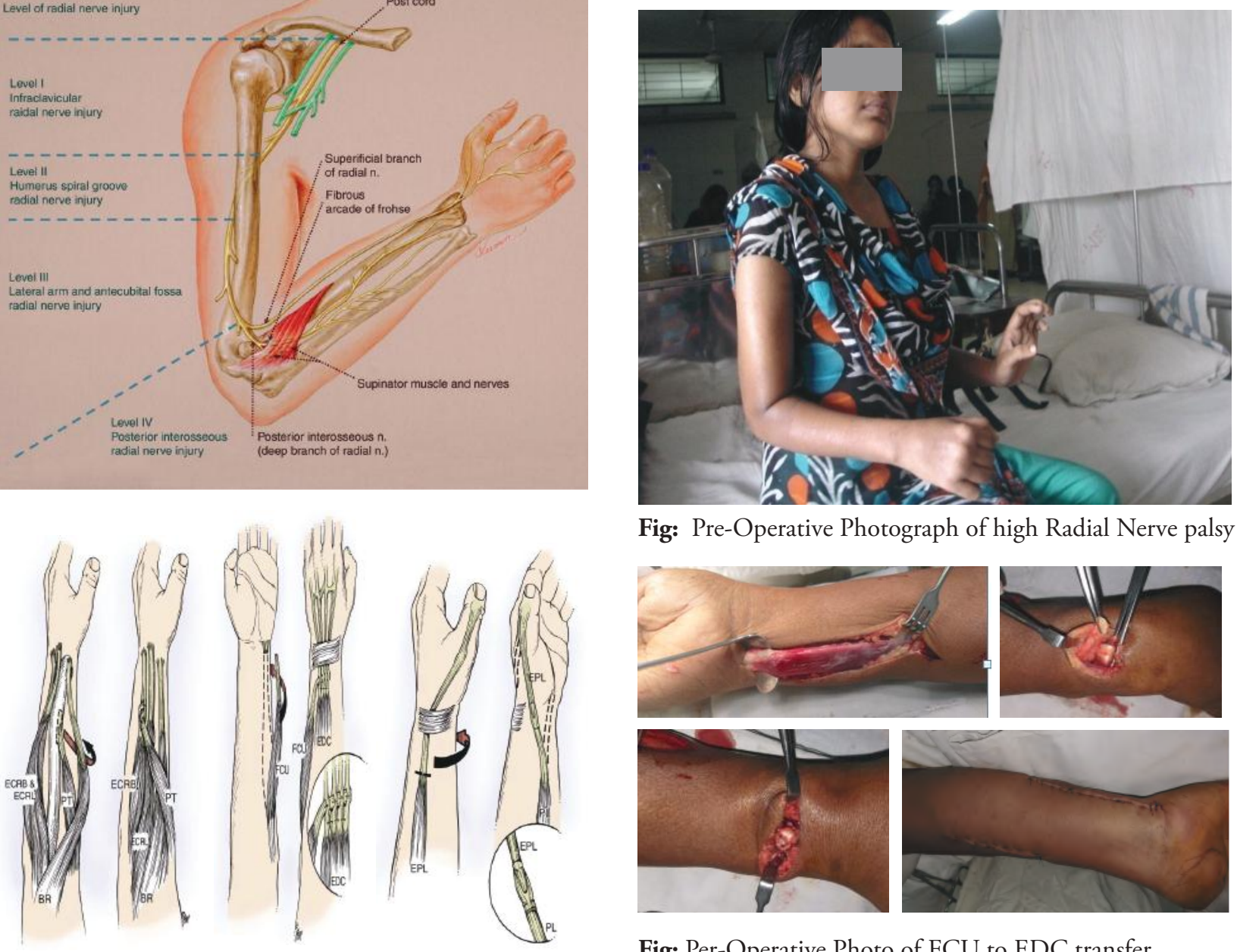

Fig: Pre-Operative Photograph of high Radial Nerve palsy



Fig: Per-Operative Photo of FCU to EDC transfer.

FCU Set of Transfer

Modified Jones / Standard Transfer



FCR Set of Transfer

Brand Transfer

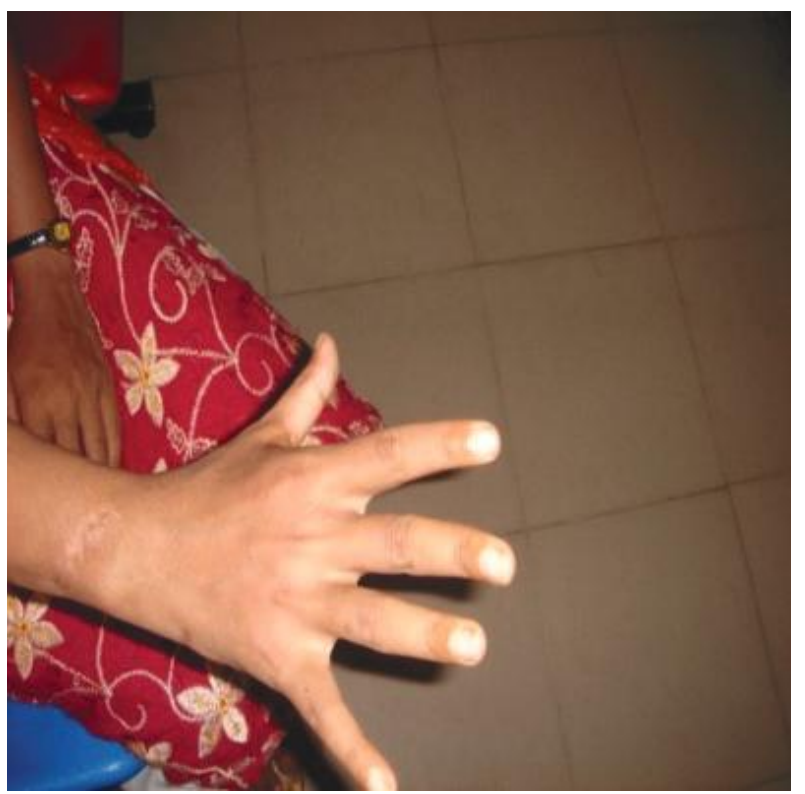

Fig: Post Operative MCP Extension 


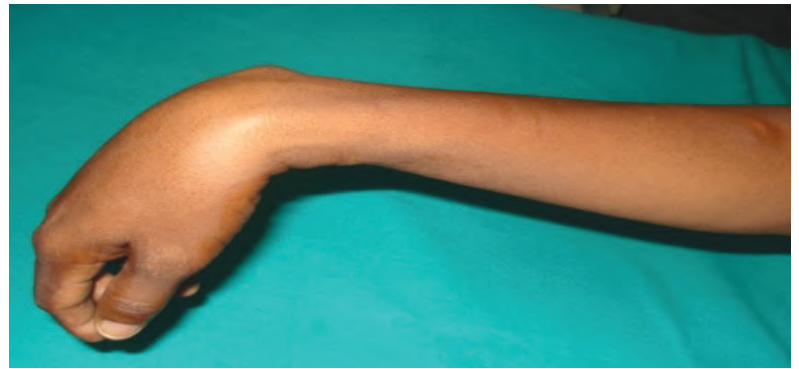

Fig: Pre-Operative Photograph of high Radial Nerve palsy
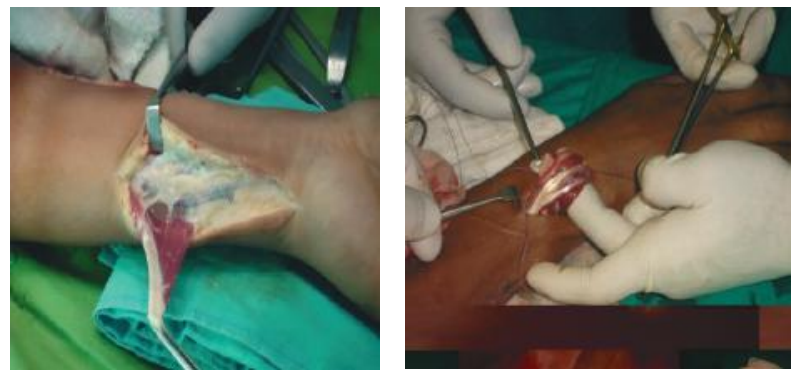

Fig: Per-Operative Photo of FCR to EDC transfer.
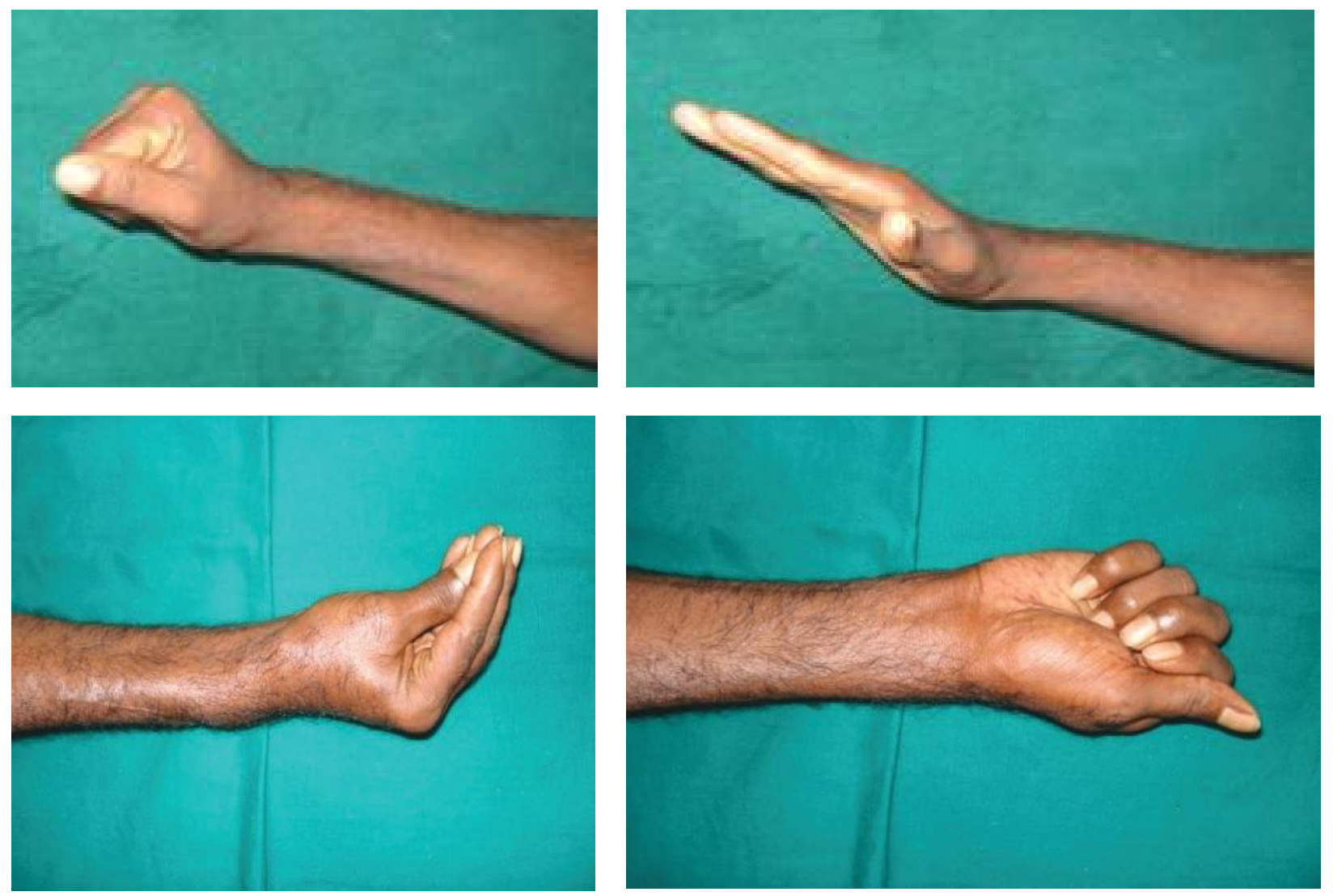

Fig: Post Operative Photograph of MCP Extension and finger with thumb flexion and extension.

\section{DISCUSSION}

Male was found predominant in this study. Out of all patients, $86.7 \%$ male were encountered both in FCR and FCU group. Zareezadeh et al. ${ }^{11}$ also found that about $98.0 \%$ of the study population was male.

Mean age was found $31.07 \pm 9.14$ years with the range of 18 to 46 years in FCR group and $33.60 \pm 10.79$ ) years with the range of 11 to 53 years in FCU group.Zareezadeh et al. and Moussavi et al. ${ }^{12}$ found no statistical significant difference in age between two groups.
After surgical intervention, soaked dressing was found more in first POD (26.7\% vs. $20.0 \%)$ than second POD (20.0\% vs $14.3 \%)$ in FCR and FCU group respectively. Moreover, hand swelling in first POD was $64.3 \%$ and $53.3 \%$ whether it was declined in second POD $26.7 \%$ and $20.0 \%$ in two groups but it remained non-significant in two groups. In a study in Iran by Zareezadeh et al. ${ }^{11}$, they also found non-significant association regarding hand swelling including forearm and wrist between FCR and FCU groups. 
Fairly satisfaction was found $6.7 \%$ cases in FCR group and $26.7 \%$ cases in FCU group at $12^{\text {th }}$ week after surgical intervention. Satisfied was found $66.7 \%$ in FCR group and $60.0 \%$ in FCU group at $12^{\text {th }}$ week after surgical intervention. Patients with very satisfied were accounted in FCR group was $26.7 \%$ and in FCU groups was $13.3 \%$ at $12^{\text {th }}$ week after surgical intervention. No statistically significant difference was found between two groups incosmetically satisfaction of patients. But Zareezadeh et al. ${ }^{11}$ found significant difference in consideration of cosmetic results of FCR and FCU groups.

At $12^{\text {th }}$ week, only $6.7 \%$ patients had extension deficit $<10^{0}$ of metacarpo-phalangeal joint in FCR group but in FCU group, that was noted $20.0 \%$. It was also found that at $12^{\text {th }}$ week, no-significant difference in level of metacarpo-phalangeal joint extension was observed.On the opposite of our study result, Zareezadeh et al. ${ }^{11}$ found significant difference between finger's active extension of FCR and FCU group $(\mathrm{p}<0.05)$.

After surgery, complications such as infection, scarring, formation of abnormal deformation was also observed. There was no significant difference between groups regarding complications. This result is agreeable with the study by Zareezadeh et al. ${ }^{11}$

According to overall satisfaction of patients with the operation, Overall satisfaction in FCR group was 93.3\% and in FCU group was $80.0 \% .93 .3 \%$ of the patients in FCR group and $86.7 \%$ patients in FCU group were able to return their previous job. Gousheh and Arasteh ${ }^{13}$ conducted a study on only FCU for tendon transfer, also reported that $86.0 \%$ of the patients were able to do their daily work after 45 days. Another study by Moussavi et al. ${ }^{12}$ who worked on tendon transfer for radial nerve paralysis and compared three methods FCU, FCR \& FDS found the ability to return to previous job without difficulty was $73.2 \%$ of the patients. As well, they also reported non-statistical significant difference in between three method counting the ability, time of return to job, satisfaction with the operation $(P>0.05)$. This findings support our study findings totally.

Surgical intervention was found excellent more in FCR group than FCU group $(26.7 \%$ vs. $6.7 \%$, p> 0.05 )according to Bincaz scale. However, $60.0 \%$ and $80.0 \%$ patients declared as good surgical intervention in FCR and FCU group respectively. Fair surgical intervention was found same in both groups which was $13.3 \%$. There was no significant difference in surgical intervention between two groups. Qattan ${ }^{14}$ observed the study results according to Bincaz scale and found that $80.0 \%$ patients showed excellent result in finger extension. Moussavi et al. ${ }^{12}$, done a DASH (disabilities of the arm, shoulder and hand) score for comparing three method of tendon transfer in radial nerve paralysis namely FCR, FCU and FDS also found non-significant association among three groups. This result is completely agreeable with our study finding.

\section{CONCLUSIONS}

In case of high radial nerve palsy,both FCR and FCU tendon transfer methods are equally effective in the improvement of fingers' extension at MCP joint.

\section{REFERENCES}

1. Davies D. Plastic and reconstructive surgery. The hand--I. British medical journal (Clinical research ed.). 1985;290(6482):1650.

2. Solomon L, Warwick D.J \&Nayagam S. Apley's system of orthopaedics and fractures, 9th ed. Hodder Arnold Co. Ltd. 2010; 224-301.

3. Ratner JA, Peljovich A, Kozin SH. Update on tendon transfers for peripheral nerve injuries. Journal of Hand Surgery. 2010;35(8):1371-81.

4. Altintas AA, Altintas MA, Gazyakan E, Gohla T, Germann G, Sauerbier M. Long-term results and the disabilities of the arm, shoulder, and hand score analysis after modified Brooks and D'Aubigne tendon transfer for radial nerve palsy. Journal of Hand Surgery. 2009;34(3):474-8.

5. Krishnan KG, Schackert G. An analysis of results after selective tendon transfers through the interosseous membrane to provide selective finger and thumb extension in chronic irreparable radial nerve lesions. Journal of Hand Surgery. 2008;33(2):223-31.

6. Lowe JB, Sen SK, Mackinnon SE. Current approach to radial nerve paralysis. Plastic and reconstructive surgery. 2002;110(4):1099-113.

7. Ropars M, Dreano T, Siret P, Belot N, Langlais F. Long-term results of tendon transfers in radial and posterior interosseous nerve paralysis. Journal of Hand Surgery. 2006;31(5):502-6.

8. Raskin KB, Wiglis ES. Flexor carpi ulnaris transfer for radial nerve palsy: functional testing of long-term results. Journal of Hand Surgery. 1995;20(5):737-42. 
9. Brand PW, Hollister A. Operations to restore muscle balance to the hand. In: Brand PW, Hollister A, eds. Clinical mechanics of the hand, 2nd ed.St. Louis: Mosby-Year Book. 1993; 180-189

10. Tsuge K. Tendon transfer for radial nerve palsy. Aust Hz J Surg, 1980;50(3):267-272.

11. Zareezadeh A, Dehghai M, Zarezadeh A, Nasri E. Results of Flexor Carpi Radialis and Flexor Carpi Ulnaris Tendon Transfers in Chronic Radial Nerve Palsy. Journal of Isfahan Medical School. 2011; 28(121): 1-10.
12. Moussavi AA, Saied A, Karbalaeikhani A. Outcome of tendon transfer for radial nerve paralysis: Comparison of three methods. Indian journal of orthopaedics. 2011;45(6):558-562.

13. Gousheh J, Arasteh E. Transfer of a single flexor carpi ulnaris tendon for treatment of radial nerve palsy. Journal of Hand Surgery. 2006;31(5):542-6.

14. Al-Qattan MM. Tendon transfer for radial nerve palsy: a single tendon to restore finger extension as well as thumb extension/radial abduction. Journal of Hand Surgery (European Volume). 2012;37(9): $855-62$. 